\title{
"LE ROY EST MORT; VIVE LE ROY!..."
}

\author{
Acácio Vaz de Lima Filho*
}

Atingiu-me brutalmente a notícia da morte - prematura — do meu grande amigo Dr. Walter Arruda Júnior, veiculada pelo jornal "O Estado de S. Paulo" em sua edição de 02 de fevereiro de 2001. Em contato com o seu distinto genitor, o advogado Walter Arruda, obtive as informações indispensáveis para escrever estes comentários, ditados pela mais pura saudade acadêmica, e fruto da "fraternidade franciscana"

Walter Arruda Júnior nasceu em São Paulo, Capital, no dia $1^{\circ}$ de outubro de 1952, sendo seus pais o já aludido Dr. Walter Arruda e Dona Nena Arruda. Realizou seus estudos primários e secundários, exclusivamente, no tradicional "Istituto Medio Dante Alighieri" na Capital do Estado, ingressando depois na Faculdade de Direito da Universidade de São Paulo (Largo de São Francisco), e na Escola de Administração Pública da Fundação Getúlio Vargas, tendo feito ambos os cursos superiores simultaneamente. Eu o conheci, e muito bem, no Largo de São Francisco, onde fui seu veterano. Bacharel em Direito, Walter trabalhou com o pai, num escritório próximo do Restaurante Itamaraty, onde cheguei a visitá-lo. Walter - um gozador, e dotado de fina ironia - mostrou-me uma infinidade de salas e corredores, e depois me disse, em tom confidencial: - "Temos aqui um estagiário, mas ele não aparece para estranhos. É o Dr. Minotauro!..." Tão apaixonados eram o pai e o filho pela velha Academia, que havia no escritório - lembro-me perfeitamente! - uma estante de alvenaria, com o formato de arcadas...

Após advogar algum tempo em companhia do pai - um profissional severo, da velha Escola - o meu amigo prestou concurso de ingresso para o Ministério Público do Estado de São Paulo, tendo sido aprovado em um dos primeiros lugares. Passou, como promotor público, sucessivamente pelas Comarcas de Mirassol, São José do Rio Preto, Tambaú, São Bernardo do Campo, Taboão da Serra, Capital, Caraguatatuba. Promotor culto e sensivel, vocacionado para a função, Walter Arruda Júnior teve um extraordinário destaque na Tribuna do Júri, mercê do seu domínio da Oratória. Humano, cumpriu à risca o VI Mandamento do Promotor de Justiça, da lavra 
de J. A César Salgado: - "Sê nobre. Não convertas a desgraça alheia em pedestal para teus êxitos e cartaz para a tua vaidade."

Desde cedo me afeiçoei ao Walter, moço dotado de uma inteligência fulgurante, possuidor de uma sólida formação humanística, orador inspirado e eloqüente, e espirituosíssimo para escrever panfletos e manifestos. Tinha um pendor muito grande para a sátira $\mathrm{e}$ - se o tivesse desejado — poderia ter se destacado até como humorista.... Poliglota, dominava o inglês, o italiano, o espanhol, o francês e o alemão. Da afeição pelo Walter, passei - naturalmente - à afeição por todos os "Mongos" "Mongos" (de "mongolóides"...), era como se auto-intitulavam aqueles Excelentes Acadêmicos, e franciscanos de quatro costados que, tendo Walter Arruda Júnior como corifeu, agrupavam-se à sua volta. Eles foram, sem sombra de dúvida, os sucessores naturais daquele "Grupo II" que, fundado e liderado por Cássio Scatena (O "Blanco"), proporcionou vida, alegria e espírito ao Pátio das Arcadas, no final da década de 60, e início dos anos 70. Por sua vez, o "Grupo II" - que tive a honra de integrar - era o sucessor da velha "Canalha." Curioso o que acontece com a Academia de Direito de São Paulo, e que chamo de seu "Traço de Lampedusa": - Tudo muda, para que tudo permaneça sempre igual!...

Os "Mongos" estavam atuantes nas Arcadas, se não me falha a memória, a partir de 1971. Eram eles Walter Arruda Júnior, Roberto Betti, Geraldo Facó Vidigal, Alexandre Thiollier Filho... e havia o Rodrigues, sobrinho do professor Silvio Rodrigues, de cujo prenome não me lembro. Aliás, soube que este moço também faleceu - antes do Walter. "Sic ei terra levis"!...Às vezes, "Paulo Eiró" (o segundo) se associava aos "Mongos", nas estudantadas.

Falar dos "Mongos" é falar de rapazes brilhantes, cultos, irrequietos, alegres e saudáveis, cheios daquela irreverência franciscana, que nunca se confundiu com a grosseria ou com o cafajestismo. Era o tempo - o glorioso tempo - em que a Faculdade de Direito de São Paulo ainda não-abdicara do seu papel de diretora da vida intelectual, cultural e cívica do Brasil. Num tal solo, dificilmente os "Mongos" moços brilhantes - se acomodariam ao figurino "oficial" do esquerdismo "bancário" Eles não haviam nascido para o que Cássio Scatena, com a sua inimitável verve, denominou o "Eixo Bancário - Empa!..." Eles haviam nascido para marcar a sua presença acadêmica - e marcaram-na.

Sob a inspiração de Walter Arruda Júnior, os "Mongos" fundaram o "P.A.M." - "Partido Acadêmico Monarquista", cujos integrantes, em suas aparições no Pátio, nas salas de aula, no "Centro Acadêmico XI de Agosto" e na pastelaria do 
"WenTo" usavam trajes da Corte dos séculos XVI e XVII!... a indumentária era conseguida na "Casa do Artista" Walter passou a ser o "Rei" (ou, como o preferia Ataliba Nogueira, insígne professor desta Casa, "El-Rei"). Roberto Betti, parecidíssimo com o papa João XXIII, era o "Bispo." Havia o arauto, o "tesoireiro real", e assim por diante.

O "Partido Acadêmico Monarquista" - P.A.M. - era uma genial brincadeira franciscana, uma "estudantada", na melhor tradição da segunda geração romântica, e com uma impressionante fidelidade aos relatos de Almeida Nogueira e Spencer Vampré...O pior é que foi levado a sério... pelos jornais "O Estado de S.Paulo" e "Jornal da Tarde"!... divertíamo-nos imenso, quando líamos no Pátio que, no Largo de São Francisco, os monarquistas tinham feito isto ou aquilo!.... Houve até um professor já falecido, à época tido e havido como intelectual dos mais acatados, que não só levou a sério o "Partido Acadêmico Monarquista" como também, perseguiu os seus integrantes... no Pátio das Arcadas, chegou-se a ouvir esta frase: - "O Professor Fulano suspendeu o Rei"...

Quando Walter ia falar, bradávamos em uníssono: - "Deus salve o Rei! Deus salve o Rei!" E, nos manifestos, Walter usava o plural majestático: — "Nós..." O "tesoireiro real" acompanhava Sua Majestade, e, após os pronunciamentos de Walter, atirava mancheias de vinténs "para a plebe". Isto geralmente acontecia no "Bar do Generoso" ou na "Pastelaria do WenTo" Walter "Rei" terminava a sua arenga e ordenava: — "Tesoireiro! Cachaça real para a plebe!..."

Walter Arruda Júnior, os seus "Mongos" e o seu "Partido Acadêmico Monarquista", foram o último bruxuleio, no Largo de São Francisco, do genuíno espírito acadêmico. A Faculdade de Direito de São Paulo tem saudade deles. E terá sempre, como terá saudades de Cassio Scatena, João Paulo Maffei, Ulisses Antonio Narciso Belfort, Luiz Amirat, Paschoal Gagliardi Netto, Araken Testa, Vital Etienne Arreguy, Luiz Antonio Ferreira de Castilho (Totonho), Gustavo Augusto de Carvalho Andrade, Fernando Teixeira de Campos Carvalho, Clóvis de Carvalho Júnior (O "Caparaó"), Abdiel Reis Dourado, e todos os que amaram, realmente, a velha Academia...

Há uma passagem da vida de Walter, da qual me orgulho de ter sido o mentor. Ele havia adquirido uma daquelas horrendas máscaras importadas, de Lobisomem, que vinham dos EUA. E eu vinha de uma das minhas muitas releituras de "O Médico e o Monstro" de Robert Louis Stevenson. Falei ao Walter da poção que o Dr. Jekill tomava, para virar Mr. Hyde. Walter - acompanhado da "canalha" em peso — foi à botica "Ao Veado D'Ouro" e mandou aviar uma receita, que seria bebida de 
um cálice, no balcão. Servida a "poção", Walter caiu ao chão, estrebuchando e dando urros pavorosos. A "canalha" o "acudiu" — isto é, o ocultou aos olhares dos curiosos. Enquanto isto, Walter vestiu a máscara de Lobisomem ẹ saiu correndo pela Rua de São Bento, com a "canalha" em seu encalço!...

Bacharel em Direito, Walter Arruda Júnior, como disse antes, foi ser promotor público. Foi para o Ministério Público, por um estilo de vida. No Exército, ele seria - e como! - da Cavalaria. Na Igreja, da Companhia de Jesus, era um lutador, um combatente. Poeta, deixou o livro "O Carrossel Metálico" que me foi presenteado por seu velho pai, que leio com carinho, e que é muito elogiado por Torrieri Guimarães.

Viveu pouco. Dele, é possível dizer o que Ibrahim Nobre, um outro franciscano, e promotor, escreveu de outros rapazes, vários deles, acadêmicos de Direito, no Mausoléu de 1932, no Ibirapuera: - "Viveu pouco, para morrer bem. Morreu jovem, para viver sempre!..."

Os pais de Walter, seus muitos amigos e seus familiares em geral, atravessam um momento de grande dor. É o próprio Walter quem, com a sua poesia, dá linimento à dor dos que ficaram. Em "O Adeus Do Sol" escreve o poeta das Arcadas:

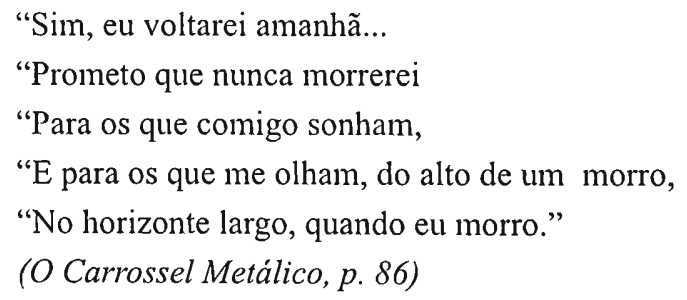

"Le Roy Est Mort; vive le Roy!..." decadente embora (e me é doloroso dizer isto), a Academia de São Paulo, a exemplo da mitológica Fênix, ainda ressurgirá das próprias cinzas. Enquanto isto, rezo — pelo Walter Arruda Júnior — e por todos os verdadeiros acadêmicos que se foram. Rezo uma oração que, em alemão, foi rezada por Theodor Körner e pelos patrióticos "Cavaleiros Mascarados de Lützov"; que em inglês, foi proferida por Lord Byron e que, em português, me foi ensinada por Tobias Barretto:

"Juntemos as almas gratas,

De colegas e de irmãos.

$\mathrm{O}$ vento que acorda as matas, 
Nos tira o livro das mãos.

A vida é uma leitura,

E quando a espada fulgura,

Quando se sente bater

No peito heróica pancada,

Deixa-se a folha dobrada,

Enquanto se vai morrer!..."

Esta oração está gravado no NOSSO Pátio das Arcadas. Walter Arruda Júnior, o meu querido amigo, está bem, eu sei. Em uma poesia sobre a morte, conclui Cássio Scatena:

"E quando enfim baixar à pedra fria,

Não estranharei muito,

Porque também és de pedra, minha Academia!"

* Acacio Vaz de Lima Filho, bacharel pelo Largo de São Francisco, Turma de 1973, mestre em Direito e doutorando pela mesma Casa, grão-oficial da "Honorífica Ordem Acadêmica de São Francisco de Assis" é orientando do professor Antonio Carlos de Campos Pedroso. Dedica estes comentários aos familiares do saudoso Dr. Walter Arruda Júnior. 